\title{
Making a Place for Escort Work: A Case Study
}

\author{
Eleanor Maticka-Tyndale, Jacqueline Lewis, and Megan Street \\ University of Windsor
}

This case study focused on the steps taken by a Canadian city bordering the United States to manage the commercial sex component of an adult entertainment package that draws many American visitors. It explored how the city dealt with the potential of community stigmatization resulting from its growing reputation as a place for easily accessible sex trade. The distinctive Canadian laws related to the sex industry, the predominantly laissez-faire attitude toward people's sex lives, and concerns about maintaining the atmosphere of safety and privacy protection preferred by many residents set boundaries to the approach that could be taken. The specific historical, geographic, social, and political location of the city figured prominently in its choice of a normalization rather than a spatialization strategy.

Sangera (1997), in her examination of the changes in sex work related to globalization, noted the emergence of a new spatial and social dimension to sex work. Historically, prostitution has concentrated near colonies of single men (e.g., military camps, port cities, colonies of migrant workers, urban centres). During times of natural disasters or social and political upheavals, masses of newly displaced and marginalised women offering sexual services in the market are drawn to these regions. Sangera refers to this as the first or traditional tier of sex work, a tier that has marked sex work throughout history. Globalization has produced a second tier. This tier is attached to the tourism industry, catering primarily to domestic and international tourists and business travellers. It grows and flourishes around major tourist and business centres. Unlike the first tier, which has remained relatively constant in size, this new tier is a growing industry designed to provide " $\mathrm{R}$ and $\mathrm{R}$ for the corporate world workforce" (Sangera, 1997, p. 11).

This paper presents a case study of Windsor, Ontario, Canada, a city that actively pursued becoming an " $R$ and R" destination for those seeking adult entertainment. While the intent was to cater to those drawn to gaming (casino, race track, bingo), the city found itself attracting tourists who also sought a commercial sex entertainment package. In this paper we focus on the steps taken by the city to manage the commercial sex sector that was part of this package and how this management reflected the specific historical, geographic, social, and political location of Windsor. We describe the development of a new social order that permitted the city to maintain a dual identity as an adult entertainment destination and a "safe, quiet, place to raise a family."1

This and similar phrases (e.g., good or ideal place to raise a family) can be seen on billboard advertisements and in real estate and visitors bureau descriptions of the city.

Address correspondence to Eleanor Maticka-Tyndale, Department of Sociology and Anthropology, University of Windsor, P.O. Box 33830, Detroit, MI 48232; e-mail: maticka@uwindsor.ca.

\section{BACKGROUND}

\section{Adult Entertainment: Tourists and Locals}

In Western culture, sexual exchange is normatively constructed as personal and private (O'Connell Davidson, 1995). The exchange of sex for money, however, is variously seen as deviant or immoral, is subjected to legislative and police control, and is stigmatized (Brock, 1998; Federal Provincial Territorial Working Group on Prostitution, 1998; Hepburn, 1993). Despite this denigration, a number of places are popular with Western travelers precisely because they provide legal and/or exotic sex for hire. Counties in the state of Nevada have legalized brothels (Albert, 2001; Decker, 1979). Amsterdam draws tourists to its commercial sex sector (Dahles, 1998; Wonders \& Michalowski, 2001). Thailand has a reputation as the destination of choice for sex tourists (e.g., Bishop \& Robinson, 1999; Formoso, 2001). The experience of travelers seeking destinations with more liberal and "exotic" sexual scenes than those at home has been described as one of liminality (Manderson \& Jolly, 1997; Ryan \& Marten, 2000; Shields, 1990). Travelers cross a threshold from the realities of home to a surreal world where familiar norms and mores are suspended. At home, the exotic and forbidden sexual performance found in these destinations is experienced vicariously, mediated through advertisements, media, and returning travelers' tales. When travelers cross the proscenium to become part of the performance, they move into liminal space. As Ryan and Marten comment, they "possess a temporal liminality by reason of being outside of their normal occupation and place" (2000, p. 143). They are "betwixt and between," in a socially condoned marginality, where they are bound neither by the mores of home nor those of the host community (Clift \& Gabrowski, 1997). When they return home, they again cross the proscenium, leaving the exotic behind and returning to the normality of their home world. They can treat their time away as a temporary break from reality, like a dreamworld where whatever happened stayed in the dream, not following them into the realities of wakefulness (Maticka-Tyndale \& Herold, 2003). 
The relationship of residents to the exotic place is not, however, one of liminality. This place is their home. They are residents of a locale where visitors come for the explicit purpose of violating the dominant norms and mores of Western sexuality. Goffman's (1963) concept of stigmatization of people has been expanded to apply to communities (e.g., Bush, Moffatt, \& Dunn, 2001; Hayden, 2000; Krase, 1979). Hayden (2000) and Krase (1979) have examined how the stigma applied to those who break with dominant norms and expectations comes to be applied to the community and how, in turn, it is applied to all residents of the community. Hayden (2000), for example, studied a community known as "backward" or "inbred"; Dahles (1998) addressed Amsterdam's reputation as being a center of "sexual liberalism and narcotic indulgence" ( $p$. 56); Hubbard (1998) studied a red-light district in England; and Tani (2002) focused on the implications of the reputation and stigma of the "prostitution area" of Helsinki, Finland, for nonprostitute residents. In each case, the reputations of communities and all their residents acquired the stigma otherwise ascribed to the few (Dahles, 1998; Hayden, 2000; Tani, 2002).

Two strategies are commonly used by communities to deal with potential stigmatization: spatialization and normalization (Hayden, 2000). When applied to the stigma of sex work, spatialization physically and socially isolates, restricting sex work to a fixed location that is treated as separate from and not reflective of the true character of the community and its residents. "Red-light districts" in cities and brothels isolated in small, rural Nevada counties keep sex work contained and apart (Albert, 2001; Decker, 1979; Hubbard, 1998; Tani, 2002). Sex workers themselves may value and reinforce spatialization. It helps to keep their work and private lives separate (MatickaTyndale, Lewis, Clark, Zubick, \& Young, 1999). Those who live in or near the red-light districts, however, carry the reputation of the district (e.g., Tani, 2002), and local residents often battle to keep sex work out of their neighborhoods. In normalization, the stigma-bearing characteristic is transformed from the exceptional and extraordinary, worthy of stigmatization, to the mundane and ordinary, no longer worthy of notice (Hayden, 2000). In sex work, this typically occurs through decriminalization, as in Amsterdam, or through local norms and customs that absorb sex work and sex workers into the mundane, as is the case in Thailand (Bishop \& Robinson, 1999; Metcalfe \& Maticka-Tyndale, 1997).

\section{Policing Sex Work in Canada}

In Canada, the exchange of sex for money is not prohibited in law (Criminal Code of Canada, 1985). While sex work per se is not illegal, a number of activities associated with it are. According to the Criminal Code, it is illegal to keep or be found in a common bawdy-house (s. 210); provide directions to or transport someone to a bawdy house (s. 211); procure or live on the avails of prostitution (s. 212); communicate in a public place for the purpose of prostitution (s. 213); and purchase sexual services from someone under the age of 18 years (s. 212[4]).

These federal statutes supersede any laws, bylaws, legislation, codes, or statutes passed by lower levels of government such as provincial parliaments or city councils. However, as observed in reports from the FederalProvincial-Territorial Working Group on Prostitution (1995a, 1995b, 1998), police often take local policies and situations into consideration in law enforcement. A common approach to enforcement of prostitution-related statutes is to wait for complaints to be made or for violations of other sections of the Criminal Code to be evident before taking action (Larsen, 1992).

\section{Windsor: A New Adult Entertainment Destination}

Windsor, Ontario, a city of 200,000 inhabitants, is located at the southern tip of Canada directly across the Detroit River from Detroit, Michigan, a city of over 6 million. There is a steady, daily flow of people across the U.S.Canada border for work, shopping, and recreation, with Windsor often described as a suburb of Detroit. Residents of both countries usually look to the United States as a more urbane, exciting, and dangerous environment, and to Canada as safer, quieter, and "tamer." Crimes against persons and violent crime rates in Canada are a small fraction of those in the United States (Gannon, 2002). Handguns are illegal in Canada and many Windsorites are proud to announce that they don't lock their doors (Hornsey \& Pooley, 2003; Moore, 2003).

Windsor has historically been a center of socialist and union activity. A union-based medical insurance plan that predated government health insurance provided one of the models for the Canadian national health insurance scheme (The Windsor Star, n.d.). Elections regularly return predominantly left-wing politicians to office (even when most other regions have moved to the right). Community spirit and social capital are evidenced in one of the highest rates of per-capita giving to major charities (The Windsor Star, n.d.) and in Windsor's reputation as a community that takes care of its residents.

Considering the city's social and political profile and history, it seems ironic that it has been dubbed "Sin City" by its neighbours in the United States (Buss, 2002). The label comes from its reputation as a place where many of the "sins" prohibited by American law can be legally indulged. For example, the Province of Ontario's lower minimum age for alcohol consumption (19 years; Liquor License Act, 1990) attracts American youth from several nearby states and fuels the growth of hotels, bars, and clubs that cater to the young in the downtown core (Henderson, 2003; Hornsey \& Pooley, 2003; Patrick, 2003). Canadian federal legislation regulating the sex industry is more lenient than that in the United States. Selling sex for money (i.e., prostitution) in itself is not illegal in Canada, and total nudity is permitted in strip clubs. During the 1990s, additional events enhanced Windsor's reputation, including the opening of a 
casino (where winnings are tax free), an Ontario Provincial Court ruling permitting female public "toplessness" $(R$. v. $J a c o b, 1996)$, the licensing of personal service workers (defined as out-call escorting and massage/body-rub for remuneration) by the city (Licensing Bylaw, 1995, 1997), and the effective "legalization" of marriage for same-sex couples (Halpern v. Canada, 2003). These events and rulings, together with the long-time favourable exchange rate on the American dollar, are some of the attractions for visitors from the United States.

The event that was most notable in increasing the flow of American tourists to Windsor was the 1994 opening of an interim casino followed 4 years later by a large Las Vegas-style casino. Considerable discussion and anticipation preceded this event. Local hotels, restaurants, and merchants were encouraged to expect increases in revenue as Windsor became the destination of choice for business, convention, and tourist travellers alike. The city anticipated capitalizing on its location next door to Detroit which served as both a portal for the arrival of visitors and comprised part of the tourist package that was offered.

Consultations between the police services in Windsor and Las Vegas produced a less optimistic picture of the likely impact of the casino. Windsor police were warned that a growth in sexual commerce, drug trafficking, crimes of fraud, and invasion by organized crime would accompany the casino (Police Services Board, 1995). Based on this advice and their own investigations into the escort industry, Windsor Police Services encouraged the city council to take assertive action to prevent this "undesirable fate." They recommended that the council develop a licensing bylaw that would impose stringent control and regulation on outcall escort and body-rub services (i.e., services for which the worker goes to the customer) and assist police in collecting intelligence on these operations (Police Services Board, 1995). Initially, the City of Windsor resisted pressure from police and in February 1994 refused to pass the requested amendments to city bylaws. City councillors were concerned that the requested changes would constitute licensing prostitution and would thus circumvent the Criminal Code. The city council did, however, strike a task force to study the issue and formulate recommendations.

Anticipating that a new era was being ushered in for the commercial sex industry, we initiated a case study of the changes and their effects. We focussed on escorts and the escort service industry as the largest group of sex workers in the city who were scheduled to be brought under the control of municipal bylaws. The research was funded by Health Canada's Laboratory Centres for Disease Control, Division of STDs and HIV, under a call for proposals that examined cross-border transport of sexually transmitted infections. This paper reports a portion of the results of this study, focussing on the steps taken by the city to manage the commercial sex sector and how this management reflected its specific historical, social, and political location.

\section{METHOD}

This case study was conducted between November 1997 and May 1999 using a multimethod approach. We followed events taking place in Windsor, Ontario, through media reports both within the city and in surrounding regions and in discussions at city council meetings and various city task forces and committees. We reviewed relevant municipal bylaws and compared them to similar bylaws in other Canadian cities. We also gathered statistics on licensing and bylaw enforcement, which were updated to the end of 2002 . Semistructured, in-depth interviews were conducted with 18 escorts, 8 escort agency personnel, 12 community workers, and 9 city officials, the latter two groups including public health and social service workers, city councillors, municipal employees, and police. We selected participants using purposive sampling techniques to maximize diversity in the sample. This strategy contributed to our confidence that the conclusions we drew from the research took into account the diversity of experiences and situations relevant to the area of inquiry (Strauss \& Corbin, 1990).

\section{RESUltS}

\section{Windsor Task Force}

The task force created by Windsor's Municipal Council to study the request to use city bylaws to regulate sex work reflected a typical Canadian approach to contentious issues. The task force had broad representation with members drawn from police services, a local women's organization, the Sexual Assault Crisis Centre, the district health unit, city council, and a citizen representative. Several escorts and agency owners were invited to join the task force but declined, agreeing instead to be interviewed by the task force. The task force consulted with other municipalities, examined the mechanisms they used to control and regulate escort services, considered a detailed report and rationale for licensing escorts prepared by the Police Services Board (1995), and interviewed an agency owner and escort. Based on their work, they formulated and brought to city council a recommendation to add to the city licensing bylaw those who provide out-call "personal services," defined in the eventual bylaw as the following:

dating or escort services where the date or escort receives remuneration; outcall services where the individual attends at the private location of the individual requesting short-term companionship or personal services; massage or body-rub services where such services are provided for non-medical reasons by individuals not licensed by the Province of Ontario or any other governing body, and are provided on an outcall basis; personal modelling services provided on an outcall basis; and/or adult entertainment services, as defined in this bylaw, on an outcall basis. ${ }^{2}$ (Licensing Bylaw, 1997, clause 305/96)

\footnotetext{
${ }^{2}$ Since reports and documentation related to this bylaw most often refer to escorts and escort agencies, this is the terminology used in this paper.
} 


\section{Police Perspective}

Windsor Police Services made a strong case for structuring the bylaw so it could be used for intelligence gathering and control over the out-call sex work industry, a portion of the sex industry that they found particularly difficult to infiltrate (Police Services Board, 1995). They saw this as essential to reducing and preventing crime and to ensuring the safety of visitors and residents. As evidence for the need for such legislation the Police Services Board presented data gathered since the opening of the casino that demonstrated a sizable increase in escort advertisements in the local paper, a growth in the number of escort agencies, and an influx of out-of-town agency owners who were thought to be "testing the waters" (Police Services Board, 1995). In addition, they reported having documented the presence of 14- to 15-year-old girls working as escorts. A licensing bylaw was seen as an essential tool for cleaning up an increasingly undesirable situation (Police Services Board, 1995). As a police representative explained:

Escort work is particularly difficult to police. You can't find it. ... When it's licensed we know who they are and where they are. We can keep tabs on it.... We can prevent the worst elements from moving in.

While out-call sex work does not violate any Criminal Code statutes, according to the Windsor Chief of Police, "agencies are just fronts for peddling drugs, setting up robberies, blackmailing clients and breaking and entering rings" ("Escort services," 1996). From the perspective of the police, although escorting was not illegal, many activities associated with it were not only illegal but reprehensible by Canadian moral standards and a threat to the safety and security of the city's residents.

\section{Task Force Recommendation}

Early in 1996, the task force recommended an amendment to the city's licensing bylaw that regulated who could work in escorting and out-call body-rub or massage and how the businesses would be conducted. As one task force member representing a community-based organization explained in her interview, in framing the bylaw, members of the task force tried to strike a balance between respecting the privacy and rights of escorts by privileging concern for the autonomy, safety, and well-being of workers, and providing police with the information and control that they needed to monitor the industry. Based on interviews with an agency owner and the experience of health and social service providers who sat on the task force, the task force members concluded that it was important to emphasize three factors in the bylaw: (a) escorts should remain integrated within their local communities and not be isolated in a red-light district; (b) escorts should be able to determine their own working conditions within the limits set by law; and (c) escorts should be provided with information that could help them conduct their work safely and contribute to their overall well-being. Consequently, the task force avoided regulations that unnecessarily spatialized and isolated escorts and that set unnecessary limits on how they conducted their work, and recommended that a portion of the funds from licensing fees be used to provide information to escorts. Under the Windsor bylaw, escorts and agency receptionists may work from their homes. This differs from bylaw provisions in other Canadian municipalities that require escorts to establish offices in specially zoned areas of the city-that is, red-light districts (e.g., "Being a Bylaw," 1986). In Windsor, escorts choose where they work. Most remain at home with their families and in their communities tending to children, family, and other daily or personal tasks as they await calls. In addition, in the Windsor bylaw escorts are not required to work for an agency. Although a provision requiring escorts to work for an agency would make policing easier by limiting the number of locations police have to check, the provision was considered to unduly limit the freedom of escorts to determine their own working conditions.

\section{Windsor's Licensing Bylaw}

The amendment to the city's Licensing Bylaw (1996) covering personal service workers and agents was passed by city council in May 1996. It prescribed a minimum age (18 years) for being licensed and required applicants to submit to a police background check. Police services recommended against licensing applicants who were identified as having a recent (past 2 years) history of involvement with prostitution, illegal drugs, fraud, crimes of violence, or weapons offences. They also recommended excluding anyone with a history of "pimping" or associations with organized crime from obtaining an agency license. It was ultimately up to the city clerk, however, to decide whether to grant a license.

The bylaw set certain minimal rules for both workers and agents that determined how they conducted their business. Work, for example, had to be conducted as out-call, and workers had to carry their license when working and produce it on the request of a police officer or license inspector. Agencies were required to keep records of the calls they took and where they sent workers, and had to make their records available to police on request. The bylaw was carefully worded so that it did not refer to the potential of exchanging sex for money as part of the job. In fact, a letter from the city licensing office addressed to agency owners advised the owners not to discuss any specific services with either clients or escorts (Bertolin, 1998). The agency's task was restricted to providing a callanswering and referral service. In this way, the city and agencies alike avoided violation of section 212 of the Criminal Code. A year after passing the original amendment, the city council passed a further amendment to the bylaw stating that the city would "provide and disseminate educational information to those obtaining licenses that included: information on community resources, legal obligations, health information, financial planning information, safety and security, and empowerment" (Licensing Bylaw, 1997, CR918/97). The city clerk was directed to work with 
the Women's Incentive Centre, Sexual Assault Crisis Centre, and local health unit to produce the information.

Essentially, the City of Windsor, on advice from a task force, framed a bylaw which opted for less regulation and control than existed in other Canadian cities with similar bylaws (e.g., Calgary, Edmonton, Winnipeg), attempting to respect escorts' rights to self-determination in their work. Escorts were treated much as other independent business people both in the provisions of the bylaw and in their interactions with city representatives and offices. As some escorts said:

The city? No, I don't have any problems with them. They treat me OK.

The last time I was hassled by the cops I called the city. They said they'd get right on it. They took all my information and a few days later called me back and said they'd talked to the cops. That woman in the license office, she doesn't talk down to you, she respects you.

Both the approach taken to creating the bylaw and the bylaw contents fit with Windsor's history as a city that gives due consideration to the self-determination, health, safety, and well-being of workers. It is also in accord with the generally left-of-centre leanings of Windsor's citizens, focussing on community and public service rather than control and regulation.

By the end of 1997, 9 agencies and 128 escorts were licensed. Although numbers have fluctuated, the industry has remained relatively constant in size with 113 escorts and 12 escort agencies licensed at the end of 2002, the most recent date for which numbers were available. These join the 653 exotic dancers and 10 adult entertainment parlors (strip clubs ${ }^{3}$ ) that comprise the publicly advertised commercial sex component of the adult entertainment package available in Windsor. All of the escorts in our study reported serving American clients. In fact, police and escorts alike estimated that American clientele had increased by upwards of $80 \%$ with the opening of the casino.

\section{Normalization of Escort Work}

Licensing normalized escort work and increased its public visibility as agencies and escorts openly advertised not only in the local newspapers, but also in the telephone book and in magazines listing local attractions. Escort work was now on the same footing as many other jobs and businesses.

Although the legality of exchanging sex for money was not affected by the bylaw, by licensing escort work Windsor City Council recognized, normalized, and facilitated the legitimation of escort work in the eyes of local residents, visitors, and escorts alike. In our research, we found that it was a common belief that the bylaw had changed the legal status of escort work. Escorts held this belief and both the Canadian and American media portrayed the situation in Windsor as one of "legalized prostitution" (Bianchi, 1996).

\footnotetext{
${ }^{3}$ Exotic dancers and strip clubs have been licensed in Windsor since 1986.
}

The legitimation of escort work through licensing was seen by the escorts to provide recourse to police when necessary, to improve the behaviour of their clients, and to ensure treatment as a self-employed person, as evidenced by the following comments from escorts:

The bottom line is, it's licensed, it's legal, it's a business that people have to treat as such. So, before we were licensed anybody that was working got ripped off all the time-customers stole everything, customers got ripped off, the girls got beat up, there was nothing you could do about it because they're doing something illegal anyways.

A lot of guys are assholes, but they're a little bit scared now because we are licensed. They're a little bit leery of doing anything they might have, you know, normally done.

\begin{abstract}
A lot of people are still going to be prejudiced against us, but now that we have our license, we're self-employed. It shows we are legally working.... So, if I want to lease a car, I can say I'm an escort, here's my license. It's easier that way because before... there was no proof you were doing it.
\end{abstract}

\section{Stigma}

Despite the normalization of escort work through licensing, prejudice and stigma were not eliminated. Escorts used their own form of normalization to avoid or manage job-related stigma. Although they generally acknowledged that exchanging sex for money was part of their job, they distanced themselves from prostitution, especially streetlevel prostitution and terms commonly associated with it (e.g., whore and prostitute). One young escort commented as follows after spending a night sharing a jail cell with several street prostitutes:

I'm not like them. They're disgusting, all dirty and smelly. Several of them look like they got AIDS. I'm not anything like them, no way, I'd never be a whore.

The women we interviewed referred to themselves as escorts and emphasized that their work did not necessari$l y$ involve sexual services. The advertised escort fee covered time with an escort. Additional services were negotiated in private, and information about the services or costs was kept out of the public eye. The city in its bylaw and the agencies and independent escorts in their descriptions of their work took the "sex" out of escorting. This kept them from coming into conflict with the Criminal Code and combated the stigma associated with prostitution.

The wording in the city's bylaw also combated the stigmatization of Windsor. In the media, city representatives consistently reported that the purpose of the bylaw was to insure the safety of escorts, local residents, and clients. Customers could expect safety befitting the image of Canada as a safe place, and residents could expect their city to remain free of organized crime or threats to themselves or their children.

\section{Adult Entertainment Package and Tourism}

The escort industry in Windsor reflects the second tier of sex work described by Sangera (1997). It exists within the con- 
text of an adult entertainment package that is used to attract tourists, conventions, and business people to Windsor. It has become part of the available " $R$ and $R$ " package. The casino, strip clubs, and escorts were an integrated package. Escorts reported that the bulk of their non-local clientele came to Windsor to visit the casino and decided to take advantage of the availability of "legal" escorts. The secondtier characteristics are present not only in Windsor's draw for clientele but also in its draw for workers. The women we interviewed who came to Windsor from other regions in Canada came because they heard about the opening of the casino and that escort work was licensed. Their primary motivation for coming was the expected influx of clients drawn to the casino. They also came, however, because they felt they would be safe from victimization and would be treated better and respected because of the bylaw.

Escorts and agency owners commented that for at least some visitors, the licensing of escort services contributed to a sense that there were no restrictions or normative prohibitions related to sex work in Windsor (i.e., that it contributed to the experience of liminality). As one interviewee said, it made customers think that "everything is legal."

Despite attempts to deal with escort work using a normalization strategy, it became clear soon after passage of the bylaw that escorting was not an accepted part of the tourist package that would be advertised and endorsed by the city, its business community, or even the casino. One agency owner, for example, reported that although she had joined the local Convention and Visitors Bureau and placed advertisements in bureau publications and at the casino, her ads were removed 6 months later when the nature of her business was discovered. However, hotels in the city do provide information to their guests on local attractions, including escort services, and some of the smaller motels thrive on the industry, offering hourly rates to escorts and their clientele.

\section{Policing Threatens Normalization}

Police representatives in their interviews and the Police Services Board in their 1995 report stated that one goal of licensing was to make escorts and agency owners more comfortable reporting crimes to the police. Approximately a year after passage of the licensing bylaw, police, escorts, and agency owners reported in their interviews that this was the case. Escorts and agency owners trusted police to provide them with the same services and protections that they provided other business people. Some reported calling police when they ran into difficulties. However, the experiences that escorts and agency owners had with police more often than not left them feeling victimized rather than respected and supported as local business people. One agency owner reported the following:

I called the police when they [the escorts] said they hadn't been paid. And the police ... were horrendous....They treated the girls like garbage. And I said look, I booked them here, I know, I'm the owner of the agency, I know they've been in there 40 minutes, they should get paid. And a couple of the cops ... said, "you should expect to get ripped off and beaten up."
Normalization and legitimation of escort work were jeopardized by tactics used by the police. Escorts repeatedly told of attempts by police to manipulate them into violating Criminal Code statutes that dealt with prostitution, exposing them to potential arrest and license revocation. Two entrapment techniques were commonly reported. In one, a call was made to an agency to request an escort. When the escort arrived, attempts were made to entice her into negotiating a fee for sexual services in a public place, thereby violating the public solicitation statute (s. 213). Another technique was to call an escort who works privately and ask her to bring a friend on the "date." If she did, she was charged with violation of the federal procurement statute (s. 212) and violation of licensing regulations that require an agency license to arrange a date for another escort.

The trust that escorts and agency owners had in police was seriously eroded following a police raid of escort agencies. As one escort commented, "Before we got raided I felt that we could call the police if we had to, if there was a problem we could confront the police. Not any more." What is interesting is that the raid was called in response to a complaint by escorts that agency owners and staff were instructing them to provide "full service" (i.e., sexual intercourse) for the standard agency fee. To operate legally, agencies can charge an "answering and referral" fee, which merely covers the time that an escort spends with a client. The price for services provided during this time must be negotiated and retained solely by the escort to avoid contravention of the federal procurement statute (Lewis \& Maticka-Tyndale, 2000). Despite placing the original complaint, the escorts felt the tactics used by police were extreme and unwarranted. They merely wanted police to inform agency owners that the instructions to provide full service violated the law (s. 212). Instead, police raided several agencies, seizing agency and in some cases personal records. Several escorts were subjected to interrogation and threats of charges if they didn't disclose information about the operations of the agency. Rather than seeing the police as responding to their concerns, escorts saw them as being "heavy handed" and victimizing the very people who had asked for help.

When asked what they felt they needed to conduct their work safely, escorts typically made reference to the law: "I'd like to know what the laws are and stuff, 'cuz I'm not going to jail for this." This request puzzled us because city council had explicitly directed that information about escorts' legal obligations be provided to them. The only information that had been provided, however, was about obligations under the income tax act (Corporation of the City of Windsor, 1999). No information had been provided about laws related to exchanging sex for money - precisely the laws that were of most concern to escorts. City representatives and police alike argued that providing such information could place the city in violation of section 212 of the Criminal Code. Police representatives insisted that it was the responsibility of escorts to ensure they knew and 
abided by municipal, provincial and federal laws, ordinances and bylaws. In interviews we were reminded that section 19 of the Criminal Code clearly states that ignorance of a law cannot be used as a defence for violation of that law. However, escorts and agency owners asked "How are we supposed to find out what the laws are?"

\section{Residents}

While normalization may benefit escorts and their clients, it is important to consider how residents responded to licensing of escorts. Letters to the editor and editorials in the local media were generally unsympathetic to licensing escorts. An editorial published in the local newspaper, The Windsor Star, soon after the city council passed the bylaw bluntly stated "legalizing prostitution doesn't make it acceptable" (Bianchi, 1996). The confusion of licensing with legalization is evident in this brief quotation, a confusion that was rampant in both Canadian and American media. More to the point, this editor's comment summarized the views of most residents about the unacceptability of "prostitution." While the mood of residents may not have been one of acceptance, residents also did not protest the actions of their city council. Despite the presence of daily newspaper and radio commentaries and discussions of the proposed licensing over a period of several weeks, most city councillors reported that they had not received any calls from their constituents expressing concerns ("Council posed," 1996).

A desire for spatialization, however, was also evident among local residents. Suggestions that escorts might be living next door or that escort services were openly advertised by the city or its convention bureau were met with concern. The bylaw was acceptable as long as out-call work remained removed from the direct visibility and lives of residents and was not presented as part of the public face of Windsor.

Residents firmly rejected the label Sin City. This rejection is still evident today (e.g., Pearson, 2004; Sacheli, 2004; Sacheli \& Thompson, 2003). Police garnered local support for the licensing bylaw by focussing on its importance in keeping the city free from organized crime and crimes related to prostitution. This allowed residents to continue to see Windsor as a good place to raise a family, an oasis from the crimes that filled their television screens when they tuned in to American news broadcasts, and allowed at least some to say that they do not lock their doors.

\section{CONCLUSIONS}

Windsor's approach to out-call sex work is set within the framework of its historical, political, geographic, and social location. Historically the city has been avante-garde in its approaches to social situations and problems, such as the medical needs of its primarily working class residents or the interests that its neighbors have in what can be obtained in Canada that cannot be obtained in the United States. It is a community high in social capital, where residents financially support local causes and come to the aid of their neighbors. The development of an approach to outcall sex work was driven by the city's move to increase its tourist draw, a move that was motivated by its geographical proximity to one of the wealthiest nations in the world whose citizens have considerable disposable capital and which has the potential to send millions of tourists to Windsor. The distinctive Canadian laws related to the sex industry, the predominantly laissez-faire attitude toward people's sex lives, and a desire to maintain the atmosphere of safety and relaxed approach to personal security displayed by many Windsorites set boundaries on the approach that could be taken. Normalization rather than spatialization was privileged.

By licensing escorts, city council drew together the diverse and at times competing interests and values of residents, escorts, agency owners, police, and clients. Licensing and normalization allowed the city to maintain its image as a "clean" place with a family orientation, precisely what residents said they wanted in letters to the editor and presentations at city council meetings. Normalization provided escorts and agency owners with a sense of legitimacy. The license was proof of their status as legitimate business people. For police, licensing facilitated surveillance and intelligence gathering on an industry that they described as difficult to infiltrate. For the majority of clients who come from the United States, the publicity resulting from the licensing of escorts made it clear that in Windsor, sexual services could be purchased without the risk of arrest.

When researchers, politicians, and social activists consider the global sex industry and sex tourism, their attention typically turns to places far removed from North America (with the exception of Nevada). Windsor, Ontario, presents for the North American audience a case study of a city within the dominant North American cultural space that has taken a different approach to its sex industry. Its approach is set within the boundaries of Canadian law, local culture, and the fact that it is a close neighbor and destination of choice for hundreds of thousands of Americans.

\section{REFERENCES}

Albert, A. (2001) Brothel: Mustang ranch and its women. New York: Random House.

Being a Bylaw of the City of Calgary to Licence, Regulate and Control Body Painting Studies, Encounter Studios, Dating and Escort Services and Model Studios, City of Calgary Bylaw No. 34M86 (1986).

Bertolin, D. (1998, June 25). [Letter]. Windsor, ON, Canada.

Bianchi, D. (1996, April 19). Legalizing city's sex industry does not make it acceptable. The Windsor Star, p. A7.

Bishop, R., \& Robinson, L. (1999). Genealogies of exotic desire: The Thai night market in the western imagination. In P. Jackson \& N. Cook (Eds.), Genders and sexualities in modern Thailand (pp. 191-205). Bangkok, Thailand: Silkworm Books.

Brock, D. (1998). Making work, making trouble: Prostitution as a social problem. Toronto, ON, Canada: University of Toronto Press.

Bush, J., Moffatt, S., \& Dunn, C. (2001). 'Even the birds round here cough' Stigma, air pollution and health in Teeside. Health and Place, 7, 47-56.

Buss, D. (2002, September 29). Vices test two cities' tolerance. Marijuana proposal renews focus on Detroit, Windsor differences. Detroit News, pp. 17A, 20A. 
Clift, S., \& Gabrowski, P. (1997). Tourism and health: Risks, research and responses. London: Pinter.

Corporation of the City of Windsor. (1999). Escort resource manual. Windsor, ON, Canada: Author.

Council posed to license sex industry. (1996, April 8). The Windsor Star, p. A1, A2.

Criminal Code of Canada, R.S.C. c. C-46 (1985).

Dahles, H. (1998). Redefining Amsterdam as a tourist destination. Annals of Tourism Research, 25, 55-69.

Decker, J. F. (1979). Prostitution: Regulation and control. Littleton, CO: Fred B. Rothman and Co.

Escort services: Council's difficult choice. (1996, April 9). The Windsor Star, p. A8.

Federal Provincial Territorial Working Group on Prostitution. (1995a). Dealing with prostitution in Canada: A consultation paper. Ottawa, $\mathrm{ON}$, Canada: Department of Justice.

Federal Provincial Territorial Working Group on Prostitution. (1995b). Results of the national consultation on prostitution in selected jurisdictions. Ottawa, ON, Canada: Department of Justice.

Federal Provincial Territorial Working Group on Prostitution. (1998). Report and recommendations in respect of legislation, policy, and practices concerning prostitution related activities. Ottawa, ON, Canada: Department of Justice.

Formoso, G. (2001). Foreign bodies. Tourism and prostitution in Thailand. Anthropologie et Societe, 25, 55-70.

Gannon; M. (2002). Crime comparisons between Canada and the United States (Statistics Canada Catalogue Report No. 85-002-XIE, Vol. 21, No. 11). Ottawa, ON, Canada: Canadian Centre for Justice Statistics.

Goffman, E. (1963). Stigma: Notes on the management of spoiled identity. London: Penguin Press.

Halpern v. Canada, O.J. No. 2268 (2003)

Hayden, K. (2000). Stigma and place: Space, community, and the politics of reputation. Studies in Symbolic Interaction, 23, 219-239.

Henderson, G. (2003, October 11). Sin city hypocrisy. The Windsor Star, p. A3.

Hepburn, M. (1993). Prostitution: Would legislation help? British Medical Journal, 307, 1370-1371.

Hornsey, C., \& Pooley, E. (2003, August 23). Bawdy image haunts city. The Windsor Star, p. Al

Hubbard, P. (1998). Sexuality, immorality and the city: Red-light districts and marginalisation of female street prostitutes. Gender, Place and Culture, 5, 55-72.

Krase, J. (1979). Brooklyn, USA: The fourth largest city in America. New York: Brooklyn College Press.

Larsen, N. E. (1992). The politics of prostitution control: Interest group politics in four Canadian cities. International Journal of Urban and Regional Research, 16, 169-189.
Lewis, J., \& Maticka-Tyndale, E. (2000) Licensing sex work: Public policy and women's lives. Canadian Public Policy, 26 (4), 437-449.

Licensing Bylaw [amended], City of Windsor Bylaw No. 5900 (1995, 1997)

Liquor License Act, R.S.O. c. L. 19 s. 30(8) (1990)

Manderson, I., \& Jolly, M. (Ed.). (1997). Sites of desire, economies of pleasure: Sexualities in Asia and the Pacific. Chicago: University of Chicago Press.

Maticka-Tyndale, E., \& Herold, E. (2003). Casual sex among Australian schoolies. The Journal of Sex Research, 40, 158-169.

Maticka-Tyndale, E., Lewis, J., Clark, J., Zubick, J., \& Young, S. (1999). Social and cultural vulnerability to sexually transmitted infection: The work of exotic dancers. Canadian Journal of Public Health, 90, 19-22.

Metcalfe, K., \& Maticka-Tyndale, E. (1997). Women, culture and HIV risk in Thailand. Canadian Journal of Infectious Diseases, 8(Suppl. A), 14A.

Moore, M. (Producer). (2003). Bowling for Columbine [Motion picture]. United States: MGM Home Entertainment.

O'Connell Davidson, J. (1995). The anatomy of "free choice" prostitution. Gender, Work and Organization, 2, 110.

Patrick, K. (2003, August 23). Manhunt. The Windsor Star, p. B1.

Pearson, C. (2004, January 8). Racy web ad defended. The Windsor Star, p. A3

Police Services Board. (1995). Board decision document (Report submitted to Chief Administrative Officer of City of Windsor).

R. v. Jacob, O.J. No. 4304 (1996).

Ryan, C., \& Marten, A. (2000), Tourists and strippers: Liminal theater Annals of Tourism Research, 28, 140-163.

Sacheli, S. (2004, January 14). Risque strip club sign draws fire. The Windsor Star, p. A3.

Sacheli, S., \& Thompson, C. (2003, July 26). Sex bar plan decried. The Windsor Star, p. A1.

Sangera, J. (1997, February). In the belly of the beast: Sex trade, prostitution and globalization. Paper presented to the South Asia Regional Consultation on Prostitution, Bangkok, Thailand.

Shields, R. (1990). The system of pleasure: Liminality and the carnivalesque at Brighton. Theory, Culture and Society, 7, 39-72.

Strauss, A., \& Corbin, J. (1990). Basics of qualitative research: Grounded theory procedures and techniques. Newbury Park, CA: Sage Publications.

Tani, S. (2002). Whose place is this space? Life in the street prostitution area of Helsinki, Finland. International Journal of Urban and Regional Research, 26, 343-359.

The Windsor Star [Home page]. (n.d.). Retrieved June 13, 1997, from http://www.southam.com/windsorstar/

Wonders, N. A., \& Michalowski, R. (2001). Bodies, borders, and sex tourism in a globalized world: A tale of two cities-Amsterdam and Havana. Social Problems, 48, 545-571. 


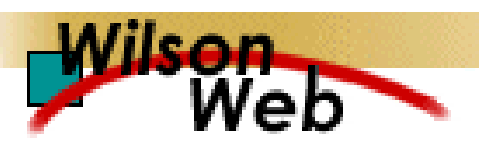

\section{COPYRIGHT INFORMATION}

TITLE: Making a Place for Escort Work: A Case Study

SOURCE: J Sex Res 42 no1 F 2005

WN: 0503202154007

The magazine publisher is the copyright holder of this article and it is reproduced with permission. Further reproduction of this article in violation of the copyright is prohibited. To contact the publisher: http://www.sssswr.org/

Copyright 1982-2005 The H.W. Wilson Company. All rights reserved. 